\title{
Role of Dentist in Forensic Investigations
}

\section{Sunit Kumar Jurel*}

${ }^{1}$ DFaculty of Dental Sciences, Upgraded KGMC, Lucknow, Uttar Pradesh, India

\begin{abstract}
Teeth can be used as a weapon of attack or defense. Dentistry has much to offer to law enforcement agencies in the uncovering and solution of crime. The permanent teeth develop throughout the first two decades of life and physiologic variations, pathologies, and effects of dental therapy may be recorded in the hard tissues of the remaining dentition throughout life and beyond. It is the role of the dentist to help extract this information and use it in the identification of the unknown body. Human teeth and dental restorations have proven to remain stable during a long time as well as in extreme situations such as fire. Therefore, dentist can play an important part in the identification of severe mutilated bodies of unknown persons. The teeth may also be used as weapon and, under certain circumstances may leave information as to the identity of the biter. Analysis of bite marks is the second major responsibility of the forensic dentist. The general practitioner has a major role to play in providing the accurate dental records on which much of forensic activity is based.
\end{abstract}

Keywords: Death; Crime; Dentition; Weapon; Bite marks, Identification; Dental restorations

\section{Introduction}

The new millennium has brought many good things in our lives for example a boom in telecommunication and information technology (Tele Dentistry) etc. , but it has also brought new challenges of terrorism, natural disasters and high rate of crime.

Dental hard tissues are extremely resistant to fire and are usually the only remains after an extended period of burial [1]. Since the late 1890s, forensic dentistry has gradually established itself as important, often indispensable, in medico legal cases, in particular for identification of the dead. The speciality of forensic dentistry generally covers three basic areas, namely;

1 Identifications of human remains

2 Litigation relating to malpractice

3 Criminal proceedings, primarily in the areas of bite-mark evaluation and abuse cases especially child abuse.

Much of its expertise is based on clinical experience, fundamental research and advances in knowledge in relation to dentistry in general [2]. Dental identification of humans occurs for a number of different reasons, and in number of different situation [3] like for the body of victim of violent crime [4], fire [5], road traffic accident, and work place accident [6]. Body can be disfigured to such an extent that identification by a family member is neither reliable nor desirable. Bodies of people who have been deceased for some time prior to discovery and those found in water also present unpleasant and difficult in identification. Through the specialty of forensic dentistry, dentist can play a small but significant role in this process. By identifying the victims of crime and disaster through guidelines and standards a dentist can assist those involved in crime investigation [7].

A number of essential characteristics of the human dentition separate humans from other animals and provide certain uniqueness such as:

1. The first of these results from the intermixing of genetic racial characteristics that have upset the natural balance between size and shape of the teeth and those of the supporting jaw bones.
2. The second is the modern chemical and structural modification of teeth resulting from disease processes or the attempt to sure such disease [8].

Testifying to the similarity or dissimilarity of a suspect's dentition to the bite mark in question is probably the most unique contribution that forensic dentistry makes to the judicial inquiry. This is a grave responsibility because a defendant's life or freedom may depend on the testimony given by the forensic dentist in court [8].

Teeth can be used to inflict serious injury on an attacker and may be the only available defensive method for victim [8]. Alternatively, it is well known that assailants in sexual attacks, including sexual homicide, rape, and child sexual abuse, often bite their victims as an expression of dominance, rage and animalistic behavior [9]. It should be worth mentioning that children who are unable to crawl cannot cause a self - inflected injury, and therefore sever bruising or fractures in a child less than six months to nine months old are almost universally inflicted non-accidentally by a second party [10].

Dental treatment itself is the biggest single contributor to the uniqueness of an individual's dentition and, along with development characteristics, is the key to enabling identification of the dead from an examination of the oral cavity.

Another important feature of the teeth is that they are the most indestructible part of the body and exhibit the least turnover of natural structure. They therefore not only survive death but also remain relatively unchanged thereafter for many thousands of years [11]. Forensic dentistry relies on this indestructibility, and its scientific advancement is designed to extract increasing amounts of identifiable information from oral structures, which, more than any other part of the

*Corresponding author: Sunit Kumar Jurel, Faculty of Dental Sciences, Upgraded KGMC, Lucknow, Uttar Pradesh, India, Tel: 09453604322; E-mail: dentistmj1110@yahoo.co.in

Received March 13, 2012; Accepted April 10, 2012; Published April 12, 2012

Citation: Jurel SK (2012) Role of Dentist in Forensic Investigations. J Forensic Res 3:148. doi:10.4172/2157-7145.1000148

Copyright: (C) 2012 Jurel SK. This is an open-access article distributed under the terms of the Creative Commons Attribution License, which permits unrestricted use, distribution, and reproduction in any medium, provided the original author and source are credited. 
body, mirror the fortunes of the individual concerned. Identification of a deceased individual or of a mark left by his or her teeth is the purpose of the forensic dentist reduced to its simplest terms, forensic dentistry has only two aims namely-

1. the relatively simple one of identification of the dead and

2. the more complex one of identifying an assailant who has used his or her teeth as weapons [11].

\section{Identification}

Death has major economic and financial ramifications for the kin arising from issue of inheritance and insurance. In criminal law, lack of identification seriously hampers murder enquires. Finally, false or unidentified cadavers offer an opportunity to illegally obtain identity documents and thereby switch identity [12]. The core of the identification procedure is comparing the post mortem remains with the ante mortem records. In civilized societies, it is socially and legally essential to identify the dead before a death certificate can be issued. Close relatives or associates who recognize facial appearance identify most human corpses. In a small percentage of cases, postmortem putrefaction or severe damage to facial features may render such identification impracticable or undesirable, and finger- prints and palm prints may be used. Natural or intentional loss of this information leaves a small number of cases where identification by traditional methods is impossible [13].

At times forensic dentistry does not offer an objective method of identification comparable to either the fingerprint or, more recently, the use of DNA technology, but it is relatively inexpensive, is capable of rapid results, and at best produces a virtually certain identification. Even when data are sparse, it may result in recognized identification that can later be confirmed by more scientific techniques [14].

\section{Species, Sex, and Race Determination}

Species determination usually presents no difficulties, unless only patchy evidence is found at the scene of a crime. There may be a fragment of mandible bearing teeth or, at worst, a small fragment of single tooth no more than a few millimetres in size [15].The traditional method of procedure in such circumstances has been to examine the fragmented tooth or bone, using comparative dental anatomy to determine that species of origin. If this is not possible from the shape of the fragment, the enamel may be examined with light or electron microscopy because the arrangement of the enamel rods or prisms differs, for example, between primate and non- primate tissue [16].

More recently, it has been shown that dentinal fluids contain specific species information. These fluids may be compared using countercurrent electrophoresis with artificially anti-sera. This technique can determine species up to at least 12 months after death. In a similar manner, remnants of cells from fragments of bone or teeth may be examined for the presence of Barr bodies or the sex chromosome status of the cells. These techniques have also been shown to be applicable for at least 12 months after death [16].

Racial determination from the skull and teeth is notoriously difficult, but separation into the main Caucasoid, Negroid, and Mongoloid racial groups may be possible using cranial and facial morphology. For example, the evaginated odontome on the occlusal preface of premolars in Chinese persons and the shoved shaped incisor of the Mongoloids (Figure1) might eliminate a Caucasoid origin [17].

\section{Facial Reconstruction}

The process of human identification can be undertaken in two ways namely-

1. In the reconstructive approach there are no ante mortem data available and the aim is to establish generic elements for general identification.

2. In the second comparative approach, records from before the individual's death, including dental charts, are used as the basis for individual identification [18].

The average thickness of soft tissues overlying various parts of the face is a rather stable characteristic. A representation of facial soft tissues can therefore be reconstructed into an unidentified skull, using traditional sculpture methods or the application of computer technology. The resulting facial model may result in the recall of a name by a member of the public. Putative identification can be used in the search for previous dental records that may confirm the identity of the deceased [19].

\section{Age Determination at Death}

The need for accurate technique for age estimation has never been greater. In last few years the need has increased for mainly two reasons namely-

1. The first is the increasing numbers of unidentified cadavers and human remains (especially in metropolian cities of india) and the

2. Second relates to cases requiring age estimation for living individuals with no valid proof of date of birth.

A very important stage in identification is an accurate determination of the age of the body. Fortunately, the human dentition follows reliable and predictable developmental sequence beginning about 4 months after conception and continuing to the beginning of the almost third decade of life, when development of all the permanent teeth is completed. Radiographs of the jaws will indicate the extent of mineralization within each individual tooth type, enabling age at death to be determined to within a few months in infants and to within a few years in teenaged specimens [20].

An important medico legal problem is whether the deceased infant was stillborn or survived birth with an independent existence. In the absence of soft tissues, a single primary tooth may be extracted, sectioned, and examined microscopically. The physiologic trauma of the birth event will leave permanent biologic marker in the hard tissues of the developing child at birth, and this may be visualized with

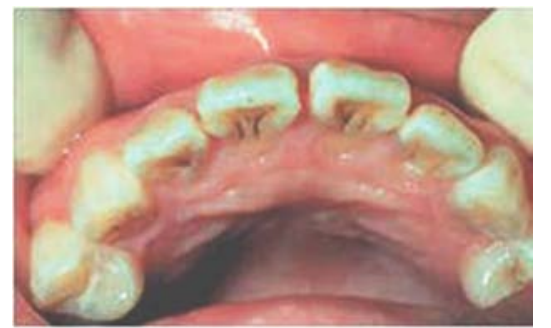

Figure 1: The evaginated odontome on the occlusal preface of premolars in Chinese persons and the shoved shaped incisor of the Mongoloids might eliminate a Caucasoid origin. 
scanning electron microscopy. This co-called neonatal line may be of extreme medico legal importance in these cases [21].

The roots of the teeth in the permanent dentition continue to grow for some years after eruption and, in the case of the third molar or wisdom tooth, growth of the root is not completed until the end of the second decade of life. Age at the time of death may therefore be determined from radiographs up to this stage [22].

Individual teeth erupt into the oral cavity in a chronological sequence that is less reliable than the developmental status, however, in younger people; a reasonable determination of age at death is possible from this feature alone. Wide racial and sex variations may need to be taken into account. The last of the permanent teeth erupt at around 18 years of age. From 20 years of age to old age, age determination at death becomes more difficult and is dependent on rather more subtle changes, which, fortunately, are permanently retained within the hard tissues of the teeth [23].

The most important and useful change in the teeth is a poorly understood biologic phenomenon whereby the tubules within the root apex become progressively mineralised as age progresses. This mineralization alters the refractive index of the dentin, rendering it transparent when examined microscopically. The extent of this root translucency may be determined by computer mapping of serial hard tissue sections of the tooth. Regression tables prepared from large numbers of teeth of known age have been used to show that it is possible to determine the age of an unidentified body within about 7 years of the correct at death [24].

Researchers working largely on animal material have recently laid the foundations for a more objective method of age determination. This depends on the finding that amino acids are built into the collagen as optically pure enantimoers of the S-aspartic acid type. Once the tooth has mineralized, these amino acids cannot be replaced. With the passage of time the aspartic acid enantiomer slowly undergoes racemization producing the opposite enantiomer, R-aspartic acid. The rate at which this change occurs has been determined, and by measuring the ratio of right-handed to left-handed enantiomeric residues in the tooth, the forensic dentist can determine the age of the individual at death [25].

The potential for application of this methodology in the archaeological and forensic fields is immense. In its present, rather crude, form, the technique is at least as accurate as any other biologic technique and will almost certainly become the method of choice for determining the age of unknown individuals by means of the teeth [25].

\section{Medical and Dental History}

Once the physical characteristics of the deceased have been established, the forensic dentist embarks on a detailed examination of the oral cavity. Unlike soft tissue surgery, the results of which may be finally obliterated during the healing process, treatment of the hard tissues does not, on the whole, repair itself. Therefore, an intervention even during childhood may remain visible throughout the life of the individual and beyond [1].

Because the teeth are subject to genetic variation, the examination of the mouth will usually commence by a description of dental anomalies such as missing teeth, misplaced or rotated teeth, unusually shaped or sized teeth, and supernumerary teeth. The status of each tooth with respect to restorations that have been placed will be recorded. The exact design and style of each restoration may not only reveal the country in which the dentist was trained. Knowledge of these variations will not directly identify the body but may well identify the origin of the dentist [26].Other aspects of therapeutic dentistry that may be of importance are the presence of orthodontic appliances, the design of which may be an indication of origin [27]. If the body possesses either a partial or complete denture, then the design and construction technique, not to mention the possibility of labeling [28].

\section{Time Elapsed Since Death}

Dentistry, distinct form of forensic pathology, has little to offer, but if death has occurred, the teeth of a corpse may take on a distinctive purplish pinkcolour that is due to accumulation of blood breakdown products in the dentinal tubules. It appears to take from 7 to 14 days before discoloration becomes apparent so this may give some gross indication of time of death [29].

\section{Comparison with Previous Records}

Final identification will have to rely on previously produced ante mortem dental records. It then becomes a relatively simple procedure to compare the information derived in the post-mortem situation with that present in the ante mortem records (Figure 2). The identification techniques are applicable to death of a single individual but also are extremely important after a mass disaster, in which there may be sever mutilation or burning of bodies, particularly in a high speed air disaster, when severe disintegration of bodies may occur. In most air disasters, $60 \%$ to $70 \%$ of all individuals are identified solely or partly through dental evidence. Forensic dentistry is the single most important technique of identification in these circumstances, and accurate dental records made and retained by the dental practitioner may be crucial in these procedures [30]

\section{Bite Mark Analysis}

Criminal cases in which a suspect or a victim has left his or her teeth marks on another person or on an inanimate object such as a candy bar, an apple, cheese or even a beer can seem to occur more frequently (Figure 3). Although in a crime involving shooting it may be possible to determine that a bullet was fired by a particular weapon, it may be more difficult to relate the weapon to the assailant. When the

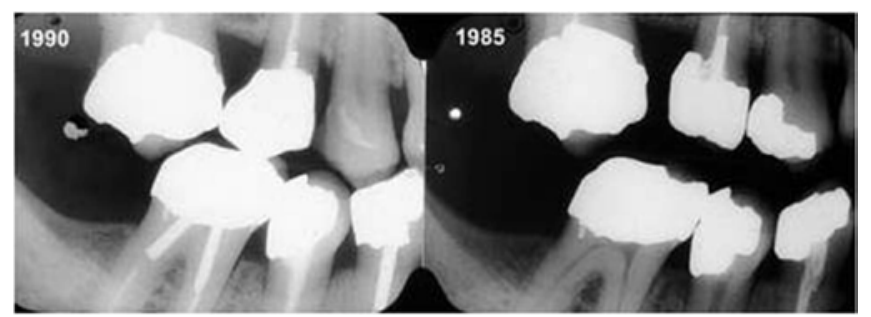

Figure 2: Comparing the information derived in the post-mortem situation with that present in the ante mortem records.

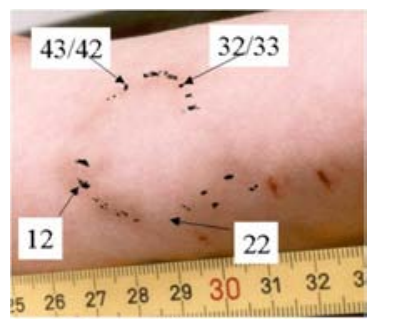

Figure 3: Bite marks on another person. 
teeth are used as weapons, they are not so easily disposed, and they can be related to the person inflicting the wound. Bite marks occur under various circumstances, usually associated with murder or rape with sexual motives. Bite marks may be identified on both the living and the dead and in the latter case may be ante mortem or post-mortem injuries [31].

\section{Bites in Human Tissue}

The scientific examination of bite-mark evidence is interesting and tough. The force required to penetrate the skin is considerable, and bites showing laceration of the tissue are necessarily aggressive in nature [32]. Identification of humans using the unique features of the teeth and jaws has been used since Roman times. The assailant may suck the soft tissues into the mouth so that images of the palatal surfaces of the teeth as well as of the incisal edges may appear. The forces required may result in petechial haemorrhages in the centre of the wound. All of these features must be analysed in describing the mark. Less aggressive bites may not penetrate the skin but will leave a partial or complete oval marks relating mainly to the anterior teeth (canine to canine). During biting, the victim (if alive) and the assailant will frequently be struggling so that teeth may produce scrape marks before the tissue is finally bitten [33]. The tissue is flexible and is distorted during the bite. If the bite is on a living person there will be post injury changes in the tissue, resulting in bleeding, swelling, and discoloration. In a dead individual there may be post-mortem changes that complicate the analysis of the mark [34].

It is important to photograph the mark with standardized techniques. Special scales with imprinted marks have been produced for this purpose to allow the degree of distortion of the photographic image to be determined. A report should be prepared at this early stage before any suspects are interviewed so that no bias is introduced into the analysis of the mark [35]. Transparent photographic overlays are prepared from these study casts at the same scale as that located over the bite mark and arranged so that one can compare the characteristics of the dentition and the bite mark [30].

Unless the bite is unusually clear and possesses characteristics that are unlikely to occur in more than one dentition, it is safer to exclude suspects through these techniques rather than to implicate them [33].

\section{Bites in Other Materials}

Criminals may, from time to time, leave their dental signature in bitten apples [36], chocolate [37], cheese, or other foods [38] left at the scene of a crime. There are cases in which assailants have bound victims with adhesive tape and torn off section of the tape with their teeth, leaving identifiable bite marks on the tape. The same principles of analysis apply as in the case of tissue bites, but bites in artificial substances of foods can often yield more information because of the lack of distortion of the material and its ability to make a good impression of the biting edges of the teeth [39].

In all types of bites, it is important that, before the materials are handled, swabs are taken to test for possible salivary contamination because this step may reveal the blood group of the assailant. If the saliva contains intraoral cellular material, DNA analysis may be possible [9].

\section{Non-Human Bites}

Bites may be left on human victims or on artefacts by animals. Most often these animals are dogs, cats, or rodents (Figure 4). The

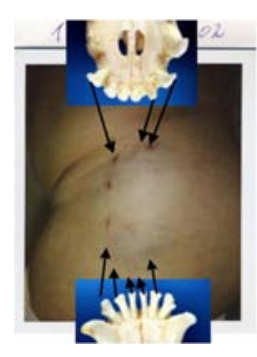

Figure 4: Bites mark on human body by an animal (dogs, cats, or rodents).

character of the bite is dependent on the dentition of the animal; the classic carnivore bite is four puncture wounds produced by the large and aggressive canine teeth of these animals, rats may produce multiple small lacerations from incisor teeth or make lacerations by slashing their razor-sharp incisors form side to side [10].

\section{Lip Prints}

The use of lip prints for human identification was first suggested in 1950 and research was carried out on lip prints in the 1960s and early 1970s, resuming in the last few years. Although lip print identification has been utilized in court in isolated cases more research needs to be conducted in this field with regard to confirmation of uniqueness, and the collection and interpretation of evidence [40].

\section{Conclusions}

Forensic Dentist may play a major role in identification of those individuals who cannot be identified. Recent tragedies and past and present situations have increased awareness concerning the importance of forensic dentistry in identification of victims. Forensic dentistry is not yet fully introduced into the dental curriculum as a subject. Hundreds of cases are seen every year in India relating to identification problems and bite mark analysis.

Moreover, the likelihood of future disasters due to terrorism, earthquakes and other causes require the dental profession in India to prepare for an expanded role that would be in bioterrorism response, crime or in civil proceedings. Dentistry has an important role in the recognition of abuse among persons of all ages. Dentist have a major role to play in keeping accurate dental records and providing all necessary information so that legal authorities may recognize malpractice, negligence, fraud or abuse, and identify unknown humans. Currently, there is no agreement among forensic dentists about the uniqueness of the dentition or behaviour of human skin during biting. Although these issues have never been proven scientifically, much research is needed to prove suspicions that human dentition is unique. Last but not the least forensic dentistry is an important science and must be treated as such.

\section{References}

1. Phillips VM (1993) The role of forensic dentistry in South Africa. Med Law 12 487-91.

2. Syrjanen SM, Sainio P (1990) Forensic dentistry - recent development towards an independent discipline in modern dentistry. Proc Finn Dent Soc 86: 157-170.

3. Weedn VW (1998) Postmortem identifications of remains. Clin Lab Med 18 115-137.

4. Whittaker DK, Richards BH, Jones ML (1998) Orthodontic reconstruction in a victim of murder. Br J Orthod 25: 11-14.

5. Andersen L, Juhl M, Solheim T, Borrman H (1995) Odontological identification of fire victims_-potentialities and limitations. Int J Legal Med 107: 229-234. 
6. Dorion RB (1990) Disasters big and small. J Can Dent Assoc 56: 593-598.

7. American Board of Forensic Odontology (1997).

8. Furness J (1981) A general review of bite-mark evidence. Am J Forensic Med Pathol 2: 49-52.

9. Webb DA, Sweet D, Hinman DL, Pretty IA (2002) Forensic implications of biting behavior: a conceptually underdeveloped area of investigation. J Forensic Sci 47: 103-106.

10. Whittaker DK (1990) Macdonald DG A Color Atlas of Forensic Dentistry, London Wolfe Medical.

11. Whittake DK, Rawle LW (1987) The effect of conditions of putrefacetion on species determination in human and animal teeth. Forens Sci Int 35: 209-212.

12. Ritz-Timme S, Cattaneo C, Collins MJ, Waite ER, Schutz HW, et al. (2000) Age estimation: the state of the art in relation to the specific demands of forensic practise. Int J Legal Med 113: 129-136.

13. Pretty IA, Sweet D (2001) A look at forensic dentistry-Part 1: The role of teeth in the determination of human identity. Br Dent J 190: 359-366.

14. Liversidge HM, Lyons F, Hector MP (2003) The accuracy of three methods of age estimation using radiographic measurements of developing teeth. Forensic Sci Int 131: 22-29.

15. Ganswindt M, Ehrlich E, Klostermann P, Troike WG, Schneider V (2003) Bone finds: a challenge to forensic science. Leg Med 5: S382-S385.

16. Davis EC, Ireland EJ, Carr R (2004) Human or not? A forensic dental case. LDAJ Winter 63: 34-35.

17. Kittelson JM, Kieser JA, Buckingham DM, Herbison GP (2002) Weighing evidence: quantitative measures of the importance of bitemark evidence. J Forensic Odontostomatol 20: 31-37.

18. Oliveira RN, Melani RF, Antunes JL, Freitas ER, Galvao LC (2000) Postmortem tooth loss in human identification processes. J Forensic Odontostomatol 18 32-36.

19. Bowers CM, Johansen RJ (2002) Photographic evidence protocol: the use of digital imaging methods to rectify angular distortion and create life size reproductions of bite mark evidence. J Forensic Sci 47: 178-185.

20. Whittake DK, Llewelyn DR, Jones RW(1975) Sex determination form necrotic pulpal tissue. Br Dent J 139: 403-405

21. Foti B, Lalys L, Adalian P, Giustiniani J, Maczel M, et al. (2003) New forensic approach to age determination in children based on tooth eruption. Forensic Sci Int 132: 49-56

22. Mesotten K, Gunst K, Carbonez A, Willems G (2003) Chronological age determination based on the root development of a single third molar: a retrospective study based on 2513 OPGs. J Forensic Odontostomatol 21: 31 35 .
23. Lampe H, Roetzscher K (1994) Forensic odontology: age determination from adult human teeth. Med Law 13: 623-628.

24. Ritz S, Stock R, Schutz HW, Kaatsch HJ (1995) Age estimation in biopsy specimens of dentin. Int J Legal Med 108: 135-139.

25. Ohtani S, Utsunomiya J, Minoshima T, Yamamoto K (1994) Toothbased age estimation of an adipocerated cadaver using the amino acid racemization method. Nihon Hoigaku Zasshi 48: 279-281.

26. Merlati G, Savlo C, Danesino P, Fassina G, Menghini P (2004) Further study of restored and un-restored teeth subjected to high temperatures. J Forensic Odontostomatol 22: 34-39.

27. Salzmann JA (1974 ) Editorial: Orthodontics in forensic odontology. Am J Orthod 65: 647-648.

28. Richmond R, Pretty IA (2006) Contemporary methods of labeling denta prostheses-a review of the literature. J Forensic Sci 51: 1120-1126.

29. Ritz S, Stock R, Schutz HW, Kaatsch HJ (1995) Age estimation in biopsy specimens of dentin. Int J Legal Med 108: 135-139.

30. Soomer H, Lincoln MJ, Ranta H, Penttila A, Leibur E (2003) Dentists' qualifications affect the accuracy of radiographic identification. J Forensic Sc 48: $1121-1126$.

31. Fischman SL(2002) Bite marks.Alpha Omegan 95: 42- 46.

32. Sheasby DR, MacDonald DG (2001) A forensic classification of distortion in human bite marks. Forensic Sci Int 122: 75-78

33. Wright FD, Dailey JC (2001) Human bite marks in forensic dentistry. Dent Clin North Am 45: 365-397.

34. Rothwell BR, Thien AV (2001) Analysis of distortion in preserved bite mark skin. J Forensic Sci 46: 573-576.

35. Bernstein ML (1985) Two bite mark cases with inadequate scale references. $J$ Forensic Sci 30: 958-964

36. Rudland M (1982) The dimensional stability of bite marks in apples after longterm storage in a fixative. Med Sci Law 22: 47-50.

37. McKenna CJ, Haron MI, Brown KA, Jones AJ (2000) Bitemarks in chocolate: a case report. J Forensic Odontostomatol 18: 10-14.

38. Webster G, MacDonald DG (1981) Forensic dental aspects of bite marks in food. Health Bull (Edinb) 39: 107-111.

39. Pretty IA, Sweet D (2001) Digital bite marks overlays-an analysis of effectiveness. J Forensic Sci 46: 1385-1391.

40. Ball J (2002) The current status of lip prints and their use for identification. $J$ Forensic Odontostomatol 20: 43-46. 